\title{
O protagonismo da criança no cenário hospitalar: um ensaio sobre estratégias de sociabilidade
}

\author{
Child protagonism in the hospital setting: \\ an essay on sociability strategies
}

M artha Cristina Nunes M oreira ${ }^{1}$

Aline Duque de $M$ acedo ${ }^{1}$

\footnotetext{
${ }^{1}$ Saúde \& Brincar -

Programa deAtenção Integral à Criança H ospitalizada, Instituto Fernandes Figueira, Fiocruz. Av. Rui Barbosa $716 / 5^{\circ}$ andar, Flamengo. 22250-020 Rio de Janeiro RJ.moreira@iff.fiocruz.br
}

\begin{abstract}
In this article we discuss chronic disease and its impacts upon childhood. We discuss the experience of providing play activities for hospitalized children asa strategy to ensuretheir freedom to make choices and to question values. We discuss the notion of socialization as being different from sociability. We discuss the interactionist perspective of Child Sociology and discuss conceptually the use of play activities as a tool for humanizing relations. We conclude that there is a need for further investigations approaching children as subjects of expression and point to the potential of play as an instrument of humanization.
\end{abstract}

Key words Childhood, Chronic disease, Humanization, Child sociology
Resumo Nesse artigo, trabalhamos com a temática da doença crônica e suas marcas na infância. Re corremos à experiência da criação de espaços lúdicos no interior dos hospitais como estratégia para afirmar o lugar de sujeito da criança e sua condição de liberdade para fazer escolhas e questionar valores. Discutimos a visão da socialização como diferenciada da sociabilidade. Abordamosa perspectiva interacionista da sociologia da infância e discutimos conceitualmente a utilização do brincar como ferramenta de humanização das relações. Concluímos apontando a necessidade de realização de pesquisas que tenham as crianças como sujeitos de expressão eapontamos o potencial do brincar enquanto dispositivo de humanização e construção de referência e de uma clínica ampliada.

Palavras-chave Infância, D oença crônica, Humanização, Sociologia da infância 
Introdução

No presenteartigo, problematiza-sea vivênciacom a doença crônica na infância, utilizando como recurso para tratar de tal temática a experiência do brincar enquanto recurso terapêutico e dispositivo humanizador das relações que constroem o cotidiano do cuidado, recepção e hospitalização das crianças atendidas em um hospital terciário, referência para a saúde da criança no Rio de Janeiro. No curso deste artigo, relativiza-se uma perspectiva presentenas definições deinfância, queafirmam que o sujeito desse período, a criança, é um ser que desconhece o que se passa ao seu redor e que está submetido aos rituais de socialização e regras do mundo dos adultos.

Algumas produções das crianças que freqüentam o hospital são utilizadas como uma estratégia para reafirmar seu protagonismo, suas experiências, valorizando os significados construídos acerca do mesmo e da doença como marcas diferenciadoras. Os dados ilustrativos desta discussão advêm das reflexões sobre a prática de atendimento em espaços lúdicos e dos desenhos de crianças que freqüentam os ambulatórios do hospital. Esses espaços lúdicos organizados no interior da instituição por uma equipe profissional funcionam como salas de espera diferenciadas, contribuindo para que os procedimentos, consultas e exames se tornem menos angustiantes e sejam incorporados como uma experiência passível de elaboração por parte das crianças.

0 artigo pretende contribuir para a reflexão sobre o contexto hospitalar na vida de uma criança portadora de doença crônica e as interveniências da cultura técnica deste espaço para o processo de socialização da mesma. Destacamos inclusive a carência de produções que analisem o hospital como espaço desocialização ea criança com doença crônica como um sujeito que incorpora o hospital em sua experiência, valorizando as relações que nele constrói, a partir de uma análise pautada na literatura da sociologia da infância.

\section{A socialização no hospital como uma dimensão da sociabilidade da criança com doença crônica}

A fim de superar limites ou imposições de caráter formal, faz-se necessário ir além do conceito durkeiminiano de socialização enquanto introjeção de valores e ampliar essa perspectiva a partir da questão da sociabilidade pela vertente simmeliana ${ }^{1}$, pensando nas interações sociais em si, na for- ma como estas se estabelecem através do encontro entre adultos e crianças, e entre crianças e outras crianças. 0 princípio da sociabilidade éformulado por Simmel enquanto o compromisso de garantia ao outro de valores sociáveis, quais sejam, al egria, liberação, vivacidade, compatíveis com o máximo de valores recebidos por esse indivíduo. A base da sociedade, segundo esse autor, está na interação entre os indivíduos e, nesse jogo de reciprocidade, de relações de troca, também cabem conflitos enquanto uma possibilidade da interação social. $\mathrm{Na}$ perspectiva simmeliana, ganha destaque ainda 0 jogo entresemel hança ediferença, como dois grandes princípios do desenvolvimento humano. A diferenciação éa possibilidade de emergência do sujeito humano e de sua singularidade. Tal postulado é caro às análises que se dedicam aos estudos sobre as crianças e a infância e, no caso desse artigo, é pertinente para se pensar sobre o impacto das diferenças provocadas pela experiência de ser portador de uma doença crônica. Portanto, é possível afirmar que a socialização é uma das dimensões de expressão das relações sociais e de suas exigências, sendo englobada pela perspectiva da sociabilidade, edasnecessidades de sociação econstrução de vínculos sociais.

Em conformidade com Plaisance2, é possível dizer que a social ização é antes de tudo uma inclusão na sociedade, com um afastamento da família para experienciar outras organizações sociais, eesse processo abarca toda a vida humana, constituindo os seres humanos como seres sociais. Ao discutirmos no curso desse ensaio a experiência das crianças com doenças crônicas a partir de uma tradição sócio-antropológica3,4,5, objetivamos ressaltar o protagonismo e a expressão da experiência da criança sobre freqüentar um hospital, perceber a diferença de quem o freqüenta, indicando, por exemplo, nos desenhos, as marcas de uma doença/ deficiência.

A criança na perspectiva interacionista édestacada como ser ativo, um ator social que participa das trocas, das interações, que atribui significado aos processos de que participa na sociedade, não sendo reduzida, e nem muito menos identificada, às instituições queassumem sua socialização. Aqui cabe-nos abrir um parênteses para referir, a partir de Plaisance, duas perspectivas centrais acerca da socialização, uma referida à tradição durkei miniana, ea outra baseada na perspectiva interativa. Para a primeira, a socialização éum modelo vertical, de imposições, cujos estudosiluminam os adultos que constroem o sistema educativo, e não as crianças, meramente relegadas a receptáculos da socialização. Já na socialização segundo o modelo interati- 
vo, predomina a perspectiva da construção do ser social, de uma ordem de múltiplas negociações entre os sujeitos ligados por relações de proximidade e alteridade, na qual se forja a identidade social. N essa segunda perspectiva, o conceito de experiência é central e contribui para a análise de situações e instituições de referência para a criança com doença crônica. Isso porquese reivindica nesse artigo a necessidade de considerar que, para essa clientela de crianças, o hospital é uma instância importante no intercâmbio de valores e a criança constrói significados sobre essa experiência de viver com uma doença crônica.

Um dos sinais da transformação do espaço hospitalar a partir da presença da criança pode ser indicado na valorização da expressão lúdica, com a adequação desse espaço para a criança, com cores, mobiliário, práticas e profissionais habilitados a valorizar sua presença e construindo canais para a expressão de sua experiência enquanto criança, enos espaços de sua vida. A expressão lúdica éo mecanismo por excelência do processo deconstrução de si e de significação da criança como ser no mundo e como um sujeito digno de expressarse. Assim, no segmento de crianças que vivem com doenças crônicas, o hospital torna-se um lócus de construção de relações sociais, de expressão sobre sua experiência com a doença.

Com base nessas considerações, retomamos 0 levantamento de trabalhos referidos a à sociologia da infância realizado por Montandon ${ }^{6}$, no qual 0 papel atribuído às crianças, mesmo quando 0 assunto éa socialização das mesmas, é de passividade. As crianças não são encaradas como atores sociais, isentas de responsabilização por qualquer situação; inclusive, transformações percebidas ao longo do tempo sobre à infância foram atribuídas à atuação dos pais e até mesmo ao papel da escola, ficando a criança mais uma vez à parte. É importante destacar ainda que a chamada sociologia da infância por muitos anos teve seus estudos sempre voltados para a criança en quanto objeto de análise dentro de algum tipo de relação, que a submete aos adultos, sejam esses seus pais ou seus professores, estudando os conflitos de gerações, ou a própria instituição voltada à criança - por exemplo, a escola. Ainda são grandes os esforços no sentido de reconhecer as crianças como um grupo social, sujeitos de suas experiências e, portanto, atores sociais.

Esta passividade atribuída como característica da infância nos estudos sociológicos analisados pela autora congela a criança enquanto objeto, re ceptáculo de informações e, de certo modo, paciente de uma socialização oferecida pelas institui- ções, seja afamília ou a escola. A criança precisa ser vista para além das instituições, para desempenhar a função de ator social. Como a escolaridade é a ocupação principal da infância ${ }^{4}$, em muitos estudos sociológicos, a criança fica restrita ao papel de aluno, e os demais aspectos de seu contexto de vida não são considerados. N a socialização de uma criança, é fato que a família, a escola, o hospital (no caso das crianças doentes crônicas) desempenham papéis importantes, mas, ainda assim, a criança é 0 ator de sua própria socialização.

Delgado e Muller ${ }^{6}$ discutem a busca de superar o reducionismo biológico, substituindo-o pelo reducionismo sociológico que se apresenta como problemático e assim as crianças eos adultos devem ser vistos em sua multiplicidade de seres em formação, incompletos e dependentes, eé preciso superar o mito da pessoa autônoma e independente, como se fosse possível não pertencermos a uma complexa teia deinterdependências. A discussão das autoras pode contribuir para os estudos sobre crianças portadoras de deficiências e/ou doenças crônicas que valorizem a perspectiva de um certo "inacabamento" intrínseco ao ser humano, que o coloca potencialmente como um ser que constrói e é construído em rede. Esse caráter de inacabamento e abertura em possibilidade para o exterior, próprio do humano, contribui para reflexões que percebam uma certa integração entrea normalidadeea anormalidade eas visões e definições acerca da doença, da deficiência e da eficiência. Assim, a interdependência nos constitui e, portanto, a autonomia e a independência estão sempre referidas a um processo complexo dealteridade, reciprocidadee solidariedade, e daí devem ser relativizadas, considerando que todos nós somos, em certa medida, dependentes e limitados, já que referidos a uma necessi dade de construir vínculos sociais.

Assim, épreciso relativizar as definições que no caso do adoecimento crônico podem vir a tipificar e rotular as crianças, reduzindo-as a um aspecto deficitário e anormal, e anulando a possibilidade de tê-las como atores importantes e legítimos sujeitos de direitos que precisam de um suporte do Estado e dos equipamentos sociais para poderem expressar-se.

Por definição, no interior dos estudos da sociologia da infância e da juventude, o ser social é construído por meio demúltiplas negociações com seus próximos, sendo assim um trabalho de um ator que experimenta o mundo social enessa experimentação o transforma. Ao considerarmos a infância como uma categoria sociológica mais geral que engloba a experiência de ser criança em diferentes contextos, nos baseamos na perspectiva te- 
órica que anal isa criticamente as expectativas acerca dos comportamentos que seriam considerados mais adequados, as formas de socialização encaradas, na maior parte das vezes, como passagens naturais por instituições e mecanismos de adaptação a valores e normas que deveriam ser encarados sem conflitos ou questionamentos acerca desse campo institucional. Por exemplo, M ayall ${ }^{7}$ faz questão de destacar que as crianças e a infância como experiência tradicionalmente tiveram um baixo status no interior da sociologia. Os estudos remetiam, bem de acordo com uma inspiração da sociologia da educação, às considerações sobre projetos de socialização, pouco problematizadose remetidos ao domínio privado.

Em uma crítica acerca da noção de socialização M ollo-Bouvier ${ }^{5,8}$ afirma que a utilização dessa noção e de seus parâmetros pode gerar expectativas e uma política estigmatizante quevisa corrigir aqueles que não se socializaram ou que tiveram uma "má-socialização". Essa visão contribui para uma desconsideração de que a socialização é um processo contínuo, mas que não implica uma linearidade, que inclui crises eque implica diversos ajustes, dessocial izações eressocializações. Essa discussão baseia uma linha interacionista da noção de socialização, considerando que a criança participa como sujeito social que tanto reproduz como transforma.

\section{A consideração do hospital como espaço de referência para crianças com doenças crônicas esuas expressões}

Após a discussão encaminhada, vale ressaltar que não se pode fixar um momento de socialização da criança. Destacamos espaços de socialização, como a família, a escola, incluindo para o segmento de crianças com doenças crônicas o hospital, e seu papel de referência não só técnica, como afetiva. Para as crianças, o desenrolar do processo de socialização se dá mediado pelo seu caráter lúdico, pela brincadeira, que vai perpassar todos os momentos/situações de vida das mesmas, servindo como instrumento cultural de transmissão de valores, de construção de sociabilidade.

Percebe-se que a imagem que a criança tem do espaço hospitalar é construída paralelamente à percepção que a mesma tem de sua própria doença, destacando o que aponta $\mathrm{H} \mathrm{el} \mathrm{man}{ }^{9}$ quando afirma que crianças enfermas, apesar da pouca idade, entendem a seu modo suas enfermidades, suas causas e seu tratamento, especulando porque estão naquel a situação e quais são os cuidados que estão sendo realizados com ela, ou seja, assumem uma postura ativa semel hante a dos adultos que se encontram nessa mesma situação. Portanto, por esta mesma razão, conforme salienta este autor, é importante explicar apropriadamenteà criança o que está acontecendo, de modo que faça sentido para a mesma. E, nesta direção, o brincar é a linguagem que vai fazer sentido para a criança ${ }^{10}$. Ainda neste contexto, de acordo com pesquisas realizadas na área de pediatria por Santa Roza ${ }^{11}$, o brincar é importante forma de intervenção em saúde junto à criança hospitalizada, contribuindo para vários setores do desenvolvimento infantil. 0 modo como o sujeito lida com sua doença, suas marcas e conseqüências, vai refletir em todos os campos de sua vida. No caso da infância, a família e a escola se configuram como os principais locais de sociabilidade, e para crianças esses espaços se apresentam também como os primeiros locais onde os recursos para selidar com a doença começam a ser construídos e/ou elaborados.

Deve-se considerar que, além da escola, o hospital torna-se um ponto forte da rede social das crianças com doenças crônicas e/ ou deficiências. Essas crianças e suas famílias demonstram a necessidade de dominar as explicações técnicas sobre a doença, elaborá-las erelê-las à luz desuas experiências como usuárias do serviço de saúde. Essa ação permite que elas enfrentem as barreiras socialmente contruídas a partir do estigma da deficiência eda doença, esclarecendo equívocos e desfazendo preconceitos. Para as crianças portadoras de doenças crônicas, o hospital se torna um espaço de sociabilidade, enquanto um território de domínio comum, de encontros e desencontros, de referência e visibilidade de outras crianças e famílias com diagnósticos, tratamentos, temores e dúvidas semelhantes. Essa proximidade permite um compartilhamento econfronto deexperiências enão deixa de provocar em algumas famílias receios: referidos a projetos futuros para essas crianças, marcados por incertezas quanto ao desempenho social, capacidade de desenvolver sua sexualidade, tornar-se independente, ter sua própria família e emprego ${ }^{12}$. Levando em conta estes receios, percebemos que nos espaços lúdicos promovidos no hospital, estas famílias têm a oportunidade de descobrir o potencial de interação, criatividade e de brincar de suas crianças.

Tais espaços introduzidos no interior da organização hospitalar tornam-se locais propícios à interação efetiva entre as crianças, seus acompanhantes e a equipe de saúde, por meio da mediação produzida pelo convite para brincar. 0 convite para brincar pressupõe como sendo anterior ao prazer para brincar, a prerrogativa da liberdade 
para recusar esse mesmo convite ${ }^{13}$. Sabendo que esse convite serve como uma primeira estratégia de consideração da condição de sujeito da criança, está em questão a opção de liberdade da criança, 0 quefavorece o encontro prazeroso com uma equipe de saúde disposta a val orizar a sua ludicidade ${ }^{12}$. Valorizar a liberdade de escolha da criança já demarca uma importante diferença na construção de um ambiente mais acolhedor para a mesma. A singularidade infantil e suas expressões (brincar, recusar procedimentos de cuidado, choros, questionamentos da rotina, barulhos, reivindicações variadas, dentre outros) ficam relegadas a um segundo plano na hierarquia de importância construída pela tradição hospitalar, que privilegia a técnica, as rotinas, os procedimentos. No caso das crianças, essa imagem reafirma a perspectiva que qualifica socialmente a infância como dependente do adulto, sem direito de escolha, caracterizada pelo desconhecimento e a irresponsabilidade com 0 que se passa ao seu redor ${ }^{14}$.

Encarar com seriedade a produção das crianças significa considerá-las como sujeitos de direito e de fato, descolando a etimologia da palavra infância - o período daqueles que não falam - da identificação de que a criança é um ser menor, inclusive no campo das pesquisas em sociologia4.

0 mais importante para as crianças portadoras de doenças crônicas, que muitas vezes possuem marcas relacionadas à doença, é a atenção a sua experiência enquanto crianças e a valorização de seus mecanismos de sociabilidade, que têm no brincar um suporte importante para a expressão. Pois um olhar muito direcionado à marca corporal pode reduzir o potencial dessas crianças e impedir os recursos que ela pode desenvolver para lidar com as mesmas.

Com o intuito de trazer à tona a percepção das crianças sobre a realidade vivida pelas mesmas no quese refereao adoecimento crônico, optamos por ilustrar este artigo com desenhos realizados pelas crianças nos espaços lúdicos a partir de solicitações de profissionais que trabalham com a promoção do brincar no interior do hospital. Em um dos casos, foi solicitado a uma criança que desenhasse a si mesma (Figura 3); e, no caso dos outros dois desenhos (Figuras 1 e 2 ), foi pedido às crianças que estavam no ambiente para desenharem o hospital, ou algo sobre ele, pois tratava-se da semana comemorativa de aniversário da instituição. Apesar da produção das crianças ter sido elaborada a partir de uma solicitação, dentro de um tema específico, a forma de condução deste processo foi livre e no momento em que as mesmas estavam desenhando não houve influência alguma do profissional, inclusive, os comentários ou títulos atribuídos ao desenho partiram das crianças espontaneamente e podem nos mostrar a percepção que as mesmas têm do ambiente hospitalar e de si mesmas. Consideramos importante ilustrar este trabalho com produções próprias das crianças no intuito de reforçar a postura ativa destes sujeitos e valorizar seus modos de perceber os diversos aspectos envolvidos em seu processo de adoecimento. Nesse processo, a representação da imagem de uma outra criança, ou da sua própria, bem como o desenho do hospital, permite concretizar a doença/diferença manifestada no corpo, e o local de tratamento da mesma, que faz parte da vida regular destas crianças.

No caso das crianças que se tratam em um hospital de referência para o tratamento de diversas patologias, há um espectro de diferenças que vão desde aquelas crianças que vivem com doenças muito graves e não possuem nenhuma marca queas diferencievisualmente, atéaquelas quealém de uma grave síndrome têm a elas associado algum tipo de deficiência. Ao expressarem através do desenho (Figuras 1 e 2) quais seriam as crian-

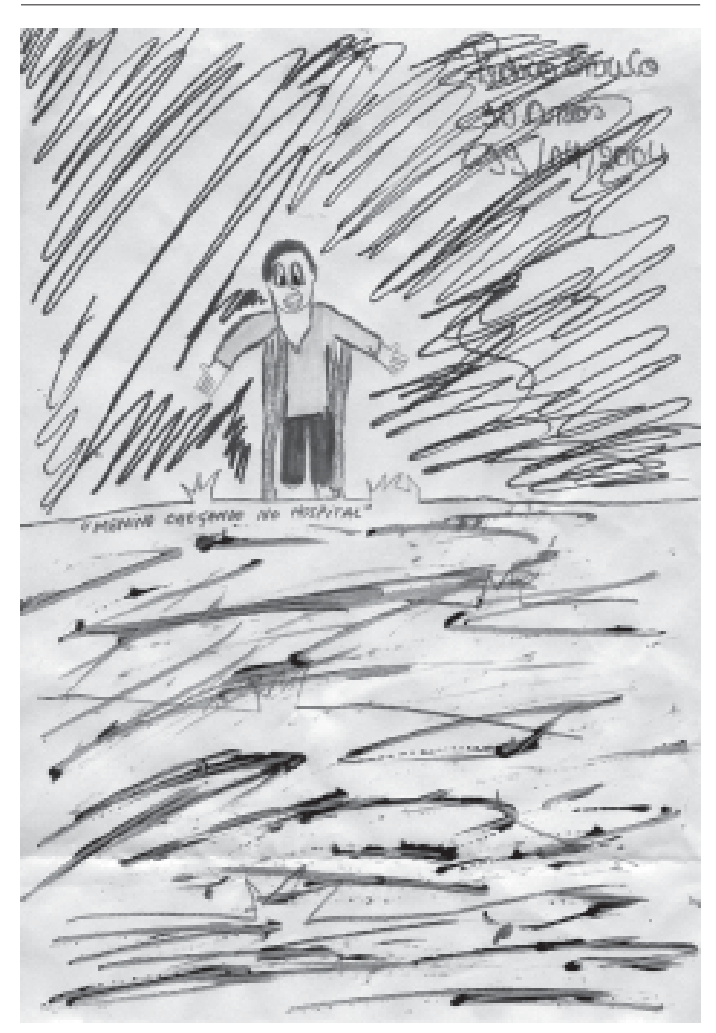

Figura 1. "M enino chegando no hospital" (menino de 10 anos que faz tratamento para alergia no hospital). 
ças que vêm se tratar no hospital, há a necessidade de demarcar o tratamento, ou a gravidade da doença pela marca física, por exemplo, pela falta de uma perna ou pelo uso de muletas:

As crianças que se tratam em um hospital terciário de alta complexidade têm plena noção de que mesmo estando em um hospital que tem um parque para brincar e pessoas responsáveis por esse espaço, há uma referência para a doença, a deficiência e até mesmo a gravidade. Essa noção é expressa nos desenhos e essa expressão não vem associada a valores discriminatórios, mas é uma expressão espontânea da diferença que marca as crianças que se tratam nesse local. Ainda que elas mesmas que desenharam não tenham nenhuma dessas marcas de deficiência, essas marcas no de senho permitem englobar o espectro da gravidade, da diferença e da falta que no repertório infantil demarca o significado da doença e é por elas percebido e expressado.

Tanto as crianças que vivem com um estigma de uma doença, quanto aquelas que não possuem visivelmentenenhuma deficiênciafísica, têm a possibilidade, na interação com outras crianças, de negociar a expectativa socialmente construída do déficit/falta decorrente da marca em uma diferença como um fato não necessariamente negativo. 0 brincar funciona enquanto mediador e facilitador para as relações de troca, em que as diferenças podem ser diluídas. Vale retomar aqui o conceito de sociabilidade no sentido de "ser um jogo onde se faz de conta que são todos iguais, e ao mesmo tempo, sefaz de conta que cada um é reverenciado em particular"1.

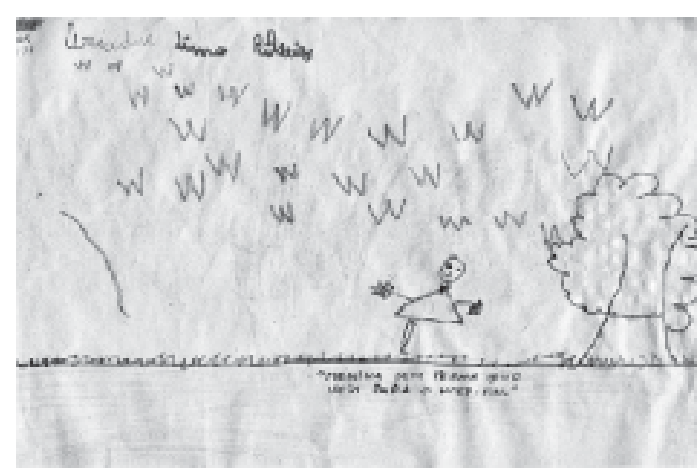

Figura 2. "M enina sem perna que veio para o hospital" (menina de 9 anos sem deficiência física, paciente do hospital).
As crianças portadoras de al gum tipo de estigma, em geral, são destacadas por esta marca mais pelos adultos. Ao contrário desses, as crianças rapidamentenaturalizam a diferença, eo que se destaca é o papel que aquela ocupa na brincadeira. Para elas, esse processo é mais espontâneo e ocorre num ciclo de reconhecimento, estranhamento, incorporação e convivência, que não depende da mediação dosadultos. N esse caso, se desenhar com uma marca de deficiência torna-seum mecanismo de expressão, elaboração e reconhecimento que facilita a convivência com a diferença (Figura 3).

0 desenho possibilita que a criança retrate aspectos da sua realidade, incluindo sua percepção sobre a diferença de forma espontânea. Essa espontaneidade é a base da expressão lúdica, que permite, através da brincadeira, um universo de negociações. Segundo Winnicott ${ }^{10}$, o brincar ocupa uma zona intermediária para além do psíquico e do comportamento. 0 brincar conduz à experiência cultural e constitui seu fundamento, tornando-se, portanto, um componente fundamental na construção da subjetividade infantil. Quando a criança aponta uma marca de outra criança, ou sua própria, é a possibilidade de desmistificar e incluir na sua experiência a diferença e o impacto que esta provoca. Ou seja, a interação lúdica cria condições para o exercício de elaboração destas marcas, confrontando dúvidas e possibilitando a transformação de expectativas.

No caso de um hospital no qual a clientela de crianças possui uma doença crônica, pode-se entender sua importância em um duplo sentido, pois, ao mesmo tempo em que o hospital é o lugar dos

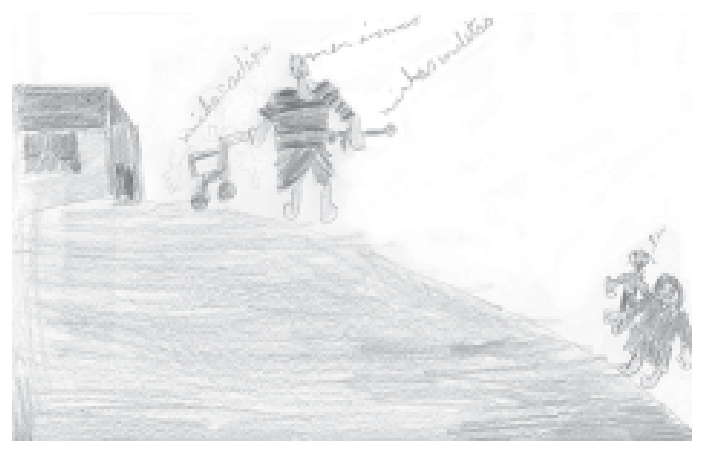

Figura 3. Criança usuária de cadeira de rodas e muletas, moradora no morro, subindo com ajuda do irmão, e no colo da mãe. 
cuidados com a doença, dos procedimentos necessários e das medicações, é também um espaço de sociabilidade para estas crianças; nesteambiente, se estabelecem novas relações, são criados espaços ondeelas têm a possibilidade de agir como crianças normais, brincando. É preciso considerar que um ambulatório pode apresentar-se tão ameaçador para a criança quanto a rotina de internação em um hospital. Segundo as autoras, vários fatores podem intervir nessa percepção de ameaça, provocando uma aversão: o tempo de espera pelas consultas, a ausência de atividades apropriadas a sua ocupação eenvolvimento, o nível dedebilidadeprovocado pela doença, a característica invasiva ou dolorosa de exames, tratamentos, a comunicação das informações sobre 0 adoecer e 0 tratamento ${ }^{8}$.

\section{Considerações finais}

A discussão acima tem como um de seus desdobramentos a constatação de que é preciso estruturar estudos com crianças portadoras de doenças crônicas e não somente sobre essas crianças. Com isso, queremos postular a necessidade de, considerando os diferentes níveis de doenças e deficiências, construir instrumentos que possibilitem a aproximação e apreensão de seus modos de viver, apropriação do espaço social e experiência com o adoecimento.

Acreditamos ser relevante refletir que o reconhecimento pela criança de sua doença, do malestar que possivelmente causa, das conseqüências, modificações ou marcas corporais que propicia, da alteração na sua rotina e na de seus pais, na percepção de que al go os preocupa emobiliza, está em jogo no cenário de suas relações. $E$ todo esse processo não merece ser negado, disfarçado ou escondido, mas pode ser adequadamente manejado pela família, recebendo suporte profissional caso necessário para isso, e pelo serviço de saúde.

Nessa perspectiva, o brincar pode funcionar como um mediador privilegiado, facilitando a incorporação pela criança da experiência da doença e de todas as suas ramificações, na sua experiência pessoal, podendo identificar em um ambientenovo como o hospital muitas coisas que domina, que pode manipular com segurança, que podem conduzir a um estado de relaxamento eliberdade. Isso vai gradativamente possibilitar a integração da criança de aspectos negativos (sofrimento, sensação de isolamento, angústia, etc.) e positivos da hospitalização (conforto, reconhecimento, autoridade sobre algo que domina, construção de parcerias, etc.) em um mesmo espaço vital: sua experiência.

M CN M oreira e AD M acedo trabalharam na análise de dados, escrita e revisão do artigo final. 


\section{Referências}

1. Simmel G. Questões fundamentais de sociologia. Rio de Janeiro: Jorge Zahar; 2006.

2. Plaisance E. Para uma sociologia da pequena infância. Educação e sociedade 2004; 25(86):221-241.

3. Montandon C. Sociologia da infância: balanço dos trabalhos em língua inglesa. Cadernos de Pesquisa Fundação Carlos Chagas 2001; 112:33-60.

4. Sirota R. Emergência de uma sociologia da infância: evolução do objeto e do olhar. Cadernos de Pesquisa Fundação Carlos Chagas 2001; 112:7-31.

5. Mollo-Bouvier S. Transformação dos modos de socialização das crianças: uma abordagem sociológica. Educação \& Sociedade 2005; 26:351-360.

6. Delgado ACC, M üller F. Sociologia da infância: pesquisa com crianças. Educação e sociedade 2005; 26:351360.

7. Mayall B. Towards a Sociology of Child Health. Sociology of Health \& IIIness 1998; 20(3):269-288.

8. Vieira T, Carneiro M. O brincar na sala de espera de um ambulatório pediátrico: possíveis significados. In: Bomtempo E, Antunha E, Oliveira V, organizadoras. Brincando na escola, no hospital, na rua... Rio de Janeiro: Wak Editora; 2006.

9. Helman C. Cultura, saúde e doença. Porto Alegre: Artes M édicas; 2003.
10. Winnicott D. O brincar e a realidade. Rio de Janeiro: Imago; 1975.

11. Santa Roza E. Um desafio às regras do jogo: o brincar como proposta de redefinição do tratamento da criança hospitalizada. In: Santa Roza E, Schueler RE, organizadores. Da análise na infância ao infantil na análise. Rio de Janeiro: ContraCapa; 1997.

12. Moreira MCN, Macedo AD. A construção da subjetividade infantil a partir da vivência com 0 adoecimento: a questão do estigma. Arquivos Brasileiros de Psicologia 2003; 55(1-2): 32-44.

13. Dantas $\mathrm{H}$. Brincar e trabalhar. In: Kishimoto TM, organizadora. 0 brincar e suas teorias. São Paulo: Pioneira; 2002.

14. Moreira MCN, Cunha CC. Repensando as práticas e dilemas no cotidiano de atenção à saúde de crianças e jovens vivendo com HIV/aids. Divulgação para Saúde em Debate 2003; 29:73-92.

Artigo apresentado em 23/05/2007

Aprovado em 26/07/2007

Versão final apresentada em 17/09/2007 